\title{
A concorrência na arte de partejar na cidade do Rio de Janeiro entre 1835 e 1900
}

\section{Competition in the arts of midwifery in the city of Rio de Janeiro from 1835 to 1900}

\author{
Helber Renato Feydit de Medeiros \\ Doutor em Saúde Coletiva/Universidade \\ Federal do Rio de Janeiro (UFRJ). \\ Rio de Janeiro - RJ - Brasil \\ helbermedeiros68@gmail.com
}

\author{
Diana Maul de Carvalho \\ Professora, Departamento de Medicina Preventiva/ \\ Faculdade de Medicina (FM)/UFRJ. \\ Rio de Janeiro - RJ - Brasil \\ dianamaul@hotmail.com
}

\section{Luiz Fernando Rangel Tura}

Professor, Departamento de Medicina Preventiva/FM/UFRJ; coordenador, Laboratório História, Saúde e Sociedade da FM/UFRJ. Rio de Janeiro - RJ - Brasil

luiztura@gmail.com

Recebido para publicação em 3 fev. 2016.

Aprovado para publicação em 1 fev. 2017.

http://dx.doi.org/10.1590/S0104-59702018005000002

MEDEIROS, Helber Renato Feydit de; CARVALHO, Diana Maul de; TURA, Luiz Fernando Rangel. A concorrência na arte de partejar na cidade do Rio de Janeiro entre 1835 e 1900. História, Ciências, Saúde - Manguinhos, Rio de Janeiro, v.25, n.4, out.-dez. 2018, p.999-1018.

\section{Resumo}

Este artigo discute a concorrência entre parteiras e médicos na oferta dos serviços de partos na cidade do Rio de Janeiro entre 1835 e 1900 . Foram analisadas as atas da congregação, os livros do curso de partos e de termos de exames de verificação de médicos, cirurgiões, boticários e parteiras da Faculdade de Medicina do Rio de Janeiro, além de anúncios e propagandas de médicos e parteiras nas colunas "Anúncios" e "Indicações Úteis" do Jornal do Commercio. Observa-se como o aumento do número de médicos-parteiros e seus discursos científicos contribuíram para que as parteiras se vissem obrigadas a diversificar a clientela, instalandose e atendendo em áreas populares e inóspitas.

Palavras-chave: medicina século XIX; profissionalização da medicina; profissionais do parto; obstetrícia.

\section{Abstract}

The article discusses competition between midwives and doctors offering birth-related services in the city of Rio de Janeiro from 1835 to 1900 . The research analyzed minutes from meetings, textbooks on births, and terms from qualification examinations for physicians, surgeons, apothecaries, and midwives at the Rio de Janeiro Medical School (Faculdade de Medicina do Rio de Janeiro), as well as announcements by and advertisements for doctors and midwives in columns featuring advertisements and useful recommendations in the Jornal do Commercio newspaper. An increase in the number of delivery physicians, and their scientific discourses led midwives to feel an obligation to diversify their clientele, consequently establishing themselves and working in lower-class and inhospitable areas.

Keywords: nineteenth-century medicine; professionalization of medicine; birth professionals; obstetrics. 
E ste trabalho é resultado do levantamento realizado em fontes primárias - livros da Faculdade de Medicina do Rio de Janeiro, anúncios e propagandas de médicos e parteiras nas colunas "Anúncios" e "Indicações Úteis" do Jornal do Commercio - e tem como referencial teórico os trabalhos de Maria Lucia Mott, sua tese de doutorado e artigos que enfatizam a questão do parto e seus agentes, tais como parteiras e médicos (Souza, 1998; Mott, 2005, 1992).

O procedimento metodológico utilizado consistiu na coleta de dados feita pelo fichamento das fontes primárias em busca das parteiras formadas no curso de partos da instituição e das estrangeiras aprovadas nos exames de suficiência da Faculdade de Medicina. Foi realizado ainda um levantamento sistemático de indícios de atividades profissionais e de dados da vida pessoal de parteiras e médicos nas propagandas e anúncios no Jornal do Commercio, entre 1831 e 1900, com um intervalo médio de cinco anos. ${ }^{1}$

O fator de motivação para este trabalho prende-se à contemporaneidade da figura da parteira. Em 2012, o Conselho Regional de Medicina do Rio de Janeiro determinou aos médicos que não dessem assistência a partos realizados em residências, já que colocavam em risco mães e bebês (Cremerj, 2012). Isso gerou protestos de associações profissionais e da sociedade civil, e culminou em uma ação ajuizada pelo Conselho Regional de Enfermagem do Rio de Janeiro (Coren/RJ) na $2^{\text {a }}$ Vara Federal do Rio de Janeiro.

Tal proibição trouxe novamente ao debate público uma antiga questão: a assistência ao parto e o papel dos diversos profissionais envolvidos, tais como enfermeiros, parteiras e doulas, além dos próprios médicos. Contudo, o importante nessa questão é observar duas situações: a contemporaneidade da figura da parteira e a demonstração de que a limitação imposta pela medicina, não só ao trabalho dessa profissional como também ao de profissionais das demais áreas da saúde, é mais antiga do que parece, remetendo-nos à lei de 3 de outubro de 1832, que consagrou o monopólio da medicina e dos médicos sobre os demais ramos das artes de curar.

Ao longo da pesquisa nas propagandas de parteiras e médicos no Jornal do Commercio, observou-se que o número de parteiras que anunciavam seus serviços nos jornais nunca foi grande e que os médicos só começaram a publicar seus serviços na arte de partejar por volta de 1855. Contudo, o número de propagandas de médicos só se sobrepôs ao de parteiras na década de 1870. Apesar disso, muitas foram as propagandas encontradas na pesquisa de ambos os segmentos entre 1835 e 1900.

Nessa pesquisa, notou-se também que a distinção social entre médicos e parteiras, ao final do século XIX, na cidade do Rio de Janeiro, parecia estar demarcada pelo espaço ocupado pelos segmentos profissionais e por suas clientelas. Os "médicos-parteiros" geralmente instalavam seus consultórios em locais habitados ou frequentados pela alta sociedade, enquanto as parteiras, normalmente, atendiam em seus domicílios, estabelecidos nas proximidades dos locais de trabalho das mulheres de segmentos sociais menos favorecidos. Porém, nem sempre fora assim. Até a década de 1850, as parteiras diplomadas em escolas estrangeiras acomodavam-se no espaço urbano sem muita concorrência entre elas ou de médicos, sofrendo apenas a concorrência das parteiras leigas - examinadas pela FisicaturaMor antes da lei de 1832 - e das comadres. ${ }^{2}$ 


\section{Médicos}

Até meados do século XIX, os médicos brasileiros, aparentemente, não se interessavam muito pela arte de partejar. Em 1835, o doutor Sigaud ${ }^{3}$ comentava que os médicos possuíam, erradamente, uma ideia generalizada de que, entre os povos primitivos e em locais de clima quente, como no Rio de Janeiro, os partos transcorriam sem qualquer intervenção, necessitando apenas de parteiras para aparar a criança (citado em Martins, 2000). Conforme descreve Santos Filho (1947), durante muito tempo os médicos brasileiros evitaram se envolver diretamente na arte de partejar por ser a atividade considerada privativa do ambiente feminino. Apesar disso, desde o princípio do século XIX, a classe médica já possuía o domínio de técnicas tidas como sofisticadas para a realização dos partos, como a manobra de Mauriceau, o uso de fórceps e a operação cesariana. O doutor Rodrigo Soares Cid de Bivar ${ }^{4}$ foi o primeiro a praticar a cloroformização obstétrica - anestesia em trabalho de parto - no Brasil, em 1848, no Hospital da Santa Casa da Misericórdia do Rio de Janeiro (Santos Filho, 1947).

A transposição do obstáculo moral que impedia os médicos de se apropriarem da medicalização do corpo feminino foi lenta e gradual. No início, associaram-se às parteiras em suas clínicas ou maternidades privadas apenas como forma de socorro no caso de problemas graves durante o parto. A partir da década de 1850, passaram a concorrer diretamente com elas na oferta do serviço, porém, tal concorrência ainda pendia em favor das parteiras devido ao hábito e às questões de decência e pudor das mulheres da sociedade. $\mathrm{O}$ aumento da busca por médicos em comparação com a procura por parteiras na concorrência pelo público feminino só começou a se desenhar em meados da década de 1870 em virtude da intensificação do discurso científico junto à opinião pública. As palestras das Conferências Populares da Glória, iniciadas em janeiro de 1874, versando sobre higiene e puericultura, tiveram um papel fundamental na apresentação dessa "cientificidade" às mulheres da alta sociedade (Carula, 2007).

Temas como o segredo médico também passaram a ser alvo de debates entre médicos e outros atores sociais. A honra das famílias, a intimidade, a reputação e o pudor deveriam ser preservados, e o segredo médico devia resguardar a questão do gerenciamento dos casamentos, da gravidez e das "doenças vergonhosas" que poderiam prejudicar a união das famílias e das fortunas. Ao médico interessava mostrar discrição, que era fundamental para ter sucesso na profissão. As associações médicas tinham consciência da importância dessa questão e não deixavam de evocar a doutrina absoluta do segredo médico como requisito da moralidade profissional (Rohden, 2006).

A promulgação da Reforma do Ensino Médico de 1879, conhecida como Reforma Leôncio de Carvalho, e a criação das cadeiras de obstetrícia e ginecologia nas duas faculdades de medicina brasileiras marcaram a consolidação do discurso médico e de sua cientificidade nessa área de atuação junto à sociedade. No entanto, persistia o problema das especialidades cujos objetos, reprodução e sexualidade,,$^{5}$ eram tradicionalmente suscetíveis à discussão que envolvia a honra da família e a autoridade de pais e maridos em relação a questões referentes à sexualidade feminina. Segundo Rohden (2006), os médicos esforçaram-se por dissociar a sexualidade do nascimento e da maternidade, e essa distinção foi condição necessária para 
que obstetras e ginecologistas pudessem ter legitimidade sem que sua atividade profissional pudesse representar uma ameaça à honra das famílias.

Interessante foi encontrar propagandas de médicos anunciando técnicas de abortamento. ${ }^{6}$ O doutor Abel Parente, na coluna "Anúncios" do Jornal do Commercio, publicada nos dias 24 e 28 de junho e 13, 26 e 27 de dezembro de 1900, propagava essa prática, na qual, segundo ele, utilizava um "invento" seu. Entretanto, informava que sua nova tecnologia, "essa pequena e inofensiva operação", somente era oferecida em certos casos: na defesa social, a fim de evitar a "multiplicação de infelizes", e quando houvesse perigo de morte para a gestante. De acordo com Rohden (2001), esse "invento" do doutor Abel Parente era um método de esterilização da mulher para evitar nova gravidez e que já havia despertado uma ruidosa controvérsia no meio médico brasileiro, incluindo juristas, a Sociedade de Higiene do Brasil e a Academia Nacional de Medicina em 1893. ${ }^{7}$

Rohden (2001) afirma que Parente foi um médico italiano radicado no Brasil. No entanto, de acordo com levantamento realizado na Base Minerva da UFRJ, o referido médico formouse na Faculdade de Medicina do Rio de Janeiro em 1876 após apresentar a tese Tratamento do reumatismo articular agudo e proposições sobre cada uma das ciências ensinadas na faculdade.

O primeiro médico-parteiro a aparecer na pesquisa no Jornal do Commercio foi o doutor Gabriel André Maria de Ploesquellec. Nos dias 8 e 29 de junho de 1855, Ploesquellec informava, na coluna "Anúncios", ser médico, cirurgião e parteiro, além de especialista em moléstias do útero, das vias urinárias, dos ouvidos e dos olhos. Ademais, curava o gálico doença venérea - e moléstias da pele por um novo sistema, atendendo na rua do Ouvidor n.24, como se pode verificar no anúncio:

O DR. G. DE PLOESQUELLEC, médico, cirurgião e parteiro tem o seu gabinete para consultas e operações, na rua do Ouvidor n.24, das 7 horas da manhã até às 2 da tarde. Especialidades: moléstias do útero, das vias urinárias, dos ouvidos e dos olhos. Cura o gálico sem azougue e as moléstias da pele por um novo sistema (Jornal do Commercio, 8 jun. 1855).

O doutor Ploesquellec formou-se na Universidade de Paris e, por volta de 1822, era cirurgião-mor do Hospital Militar na província de Goiás (Age, 2011). Casou-se em 1828 com Maria Benedicta de Souza Fortes, filha do guarda-mor da então vila de São João Del Rei, com quem teve um filho, Gabriel de Ploesquellec Fortes de Bustamante (Jannuzzi Jr., 2002), que posteriormente cursou direito na Universidade de Coimbra e foi personagem do romance português $O$ melhor casamento (Pimentel, s.d.). No entanto, como já medicava no país antes da lei de 3 de outubro de 1832, certamente foi examinado pela FisicaturaMor. Em 1846, publicou, na Corte, uma obra intitulada O livro de todos, ou manual da saúde, editada pela Tipografia de J. Villeneuve.

Em 1855, as únicas propagandas encontradas na coluna "Anúncios" do Jornal do Commercio oferecendo serviços de parto foram as duas de Ploesquellec, aumentando para nove em 1860. Até a década de 1880, quando o Jornal do Commercio dedicou a coluna "Indicações Úteis" a pequenas propagandas, o número de médicos que anunciavam seus serviços cresceu de forma irregular e oscilou bastante até a sua consolidação no mercado (ver Gráfico 1). Paradoxalmente, foram as parteiras que aproveitaram essa coluna em seu 
início; porém, em 1885, os médicos-parteiros já haviam percebido os benefícios dessa coluna do periódico, o que acarretou uma grande expansão de anúncios daquele segmento profissional.

Gráfico 1: Anúncios de parteiras e médicos no Jornal do Commercio, 1835-1900

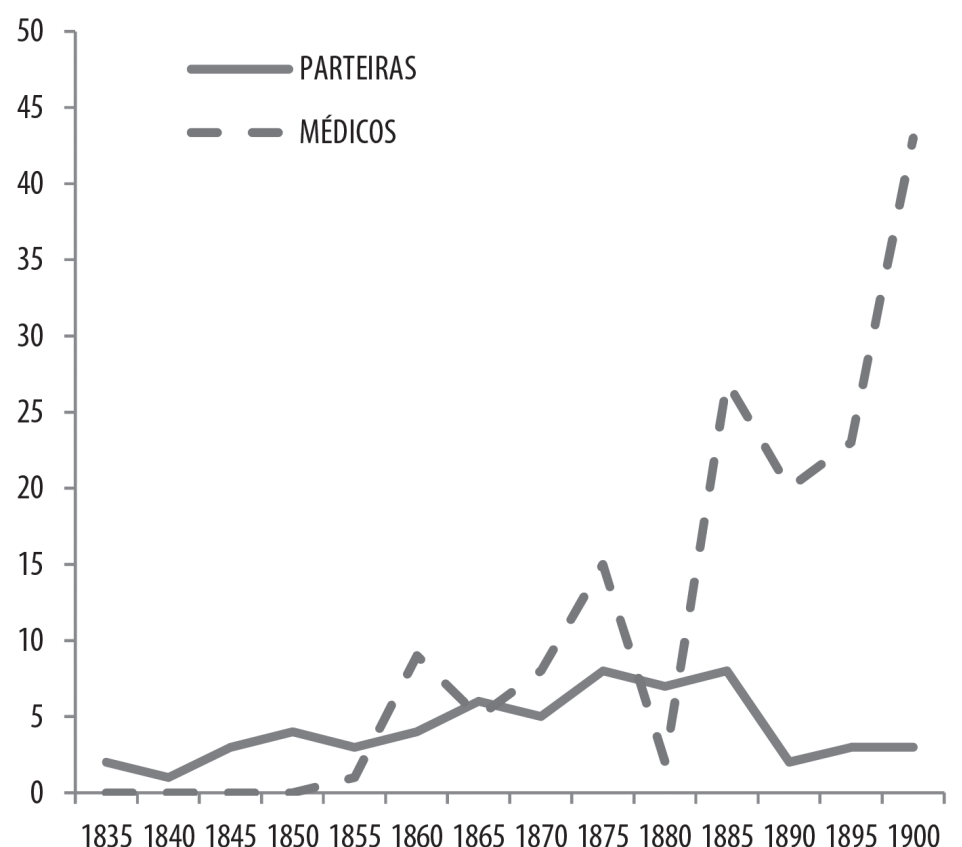

(Fonte: Jornal do Commercio, de 1835 a 1900)

Muitos foram os médicos encontrados nas propagandas do Jornal do Commercio. Alguns lentes da Faculdade de Medicina, como o visconde de Santa Isabel, que foi diretor da faculdade, e seu filho, doutor Feijó Junior; o visconde de Saboia, que também foi diretor da Faculdade de Medicina; o doutor José Maurício Nunes Garcia, filho do famoso padre de mesmo nome, que era mestre da Capela Real e o mais importante compositor brasileiro da sua época; o doutor Catta Preta, que possuía uma clínica na Praça XV, e o doutor Rodrigues Lima, responsável posteriormente pela campanha para a instalação da Maternidade das Laranjeiras. Os nomes de outros médicos não menos importantes na sociedade da Corte também foram encontrados nas propagandas, como o do doutor Carneiro Leão, barão do Paraná - filho do marquês do Paraná, eminente político do Império, que chegou a ser primeiro-ministro de Sua Majestade, o imperador dom Pedro II; e o doutor Vieira Souto, pai do famoso engenheiro de mesmo nome, que seria responsável pela modernização do porto do Rio de Janeiro.

\section{Parteiras}

Apesar de as parteiras serem mais antigas na cena do parto, até 1832 não havia um curso regular para a formação de obstetrizes no Brasil. O curso de formação de parteiras foi institucionalizado pelo artigo 19 da lei de 3 de outubro de 1832 (Brasil, 1832), que 
determinava haver um curso de parteiras ministrado pelo lente da cadeira de partos. A primeira aluna do curso de partos encontrada nos registros foi Maria Josephina Matilde Durocher. Apesar de ter sido matriculada no curso em 1833, a única menção à sua presença é a que consta na ata da sessão de 10 de março de 1834, na qual o lente de partos, doutor Felizardo Joaquim da Silva Morais, é nomeado para examiná-la "de primeiras letras" (Cedem, 1831).

Mme. Durocher (1808-1893) tornou-se a figura de maior destaque entre as parteiras no Brasil, criando um mito em torno de si. É referida como a mais célebre entre as parteiras por Anayansi Correa Brenes (1991) em artigo sobre a história da parturição no Brasil no século XIX. Maria Lúcia de Barros Mott fez um levantamento biográfico de Mme. Durocher, apresentado em tese de doutorado e também escreveu artigos sobre ela e outras parteiras. Muito elogiada, Durocher trabalhou com o lente catedrático da cadeira de partos da Faculdade de Medicina, Luis da Cunha Feijó, o visconde de Santa Isabel, sendo referida pelo doutor Fernando Magalhães como uma das parteiras mais cultas e dignas de seu ofício, ressaltando ainda sua competência e generosidade (Martins, 2000). No entanto, tendo como base os trabalhos de Mott, esta pesquisa procurou acrescentar mais informações sobre a vida pessoal e profissional das demais parteiras vistas por ela e de diversas outras que trabalharam na Corte no século XIX.

Antes da lei de 3 de outubro de 1832, não existiam parteiras formadas pelas faculdades de medicina brasileiras. Só podiam exercer a "arte de partejar" de forma legal as parteiras que fossem licenciadas ou examinadas pela Fisicatura-Mor; ${ }^{8}$ nesse caso, somente as parteiras práticas e as parteiras leigas. As parteiras práticas eram estrangeiras diplomadas em escolas europeias e registradas nas Câmaras Municipais, e as parteiras leigas não possuíam diplomas, mas eram examinadas pela prática estabelecida ao longo dos anos e atestada por autoridade competente. Já as comadres trabalhavam de forma clandestina, sem licença de qualquer autoridade (Souza, 1998).

Apesar de pouco se saber sobre a vida das parteiras práticas e leigas, foram encontrados alguns anúncios de oferta de seus serviços no Jornal do Commercio. ${ }^{9}$ Os primeiros encontrados são das parteiras Maria Clara de Moraes, leiga, e Mme. Stephanie, prática, que trabalhavam na Santa Casa de Misericórdia. A primeira publicou anúncio no dia 9 de junho de 1835. Já a segunda publicou diversos anúncios, nos dias 17 de janeiro, 4 e 10 de junho e 15 de julho do mesmo ano.

Maria Clara de Moraes, mestra parteira da Santa Casa de Misericordia, onde tem praticado muitos v.s, tem a honra de participar ao respeitável público, e principalmente à classe necessitada, a quem oferece prestar os seus serviços gratuitamente, que a podem procurar em sua casa, rua do Aljube sobrado n. 18, a qualquer hora. Aí acharão quartos mui decentes, prontificados para Sras., que serão tratadas com todo o desvelo e melindre que exigir a sua situação. Juntamente se encarrega de criar algumas crianças até as desmamar, para o que precisa de duas amas secas de capacidade. Também vende água restringente engarrafada, muito útil aplicada em banhos (Jornal do Commercio, 9 jun. 1835)

Mme. Stephanie mestra parteira da Santa Casa de Misericordia, tem a honra de participar ao respeitável Público, que ela tem na sua casa, rua da Alfandega n.158, 
primeiro andar, quartos mui decentes prontificados para Sras, onde serão tratadas com todo o asseio, desvelo, e melindre que exigir a sua situação: encarrega-se também de escravos por preços cômodos (Jornal do Commercio, 17 jan. 1835)

Ao comparar os dados de nossa pesquisa com o trabalho de Mott, tem-se a impressão de que Mme. Stephanie e "Mme. Berthou" eram a mesma pessoa. Como o sobrenome da parteira, Wernault, era difícil de ser pronunciado pelos habitantes da cidade, "Mme. Wernault" ficou popularmente conhecida como "Mme. Berthou" (Souza, 1998). ${ }^{10}$

Outra parteira leiga encontrada na pesquisa foi Clementina Rosa do Rego. Em anúncio de 18 de janeiro de 1850, avisa a suas clientes que está de mudança da Rua das Violas n.113 para a rua da Alfândega n.52, $2^{\circ}$ andar, "onde pode ser procurada a toda e qualquer hora, tanto de dia quanto de noite, por aquelas pessoas que lhe queiram fazer essa honra" (Jornal do Commercio, 18 jan. 1850).

Fora os anúncios, nada mais foi encontrado sobre a vida pessoal ou profissional de Maria Clara e de Stephanie. Já em relação a Clementina, sabe-se que exerceu a "arte" entre 1822 e 1869, ou seja, por 47 anos (Souza, 1998).

Outras parteiras também publicaram anúncios isolados no Jornal do Commercio. Muito pequenos, sem preocupação em demonstrar qualificação profissional, discurso de agradecimento ou respeitoso com suas clientes, esses anúncios podem ser pistas de comadres tentando ofertar seus serviços, apesar da falta de recursos financeiros. No primeiro e segundo anúncios, publicados em 22 de janeiro de 1880, as anunciantes apresentaram-se apenas como "a parteira", sem mencionar seus nomes. Seria para não chamar a atenção das autoridades? Para ser dirigido apenas às pessoas que as conheciam, que já haviam utilizado seus serviços?

A PARTEIRA que morou na travessa de D. Ros ... 3, mudou-se para a rua do General Pedra n.1 ... (Jornal do Commercio, 22 jan. 1880).

A PARTEIRA que morou na rua do Senhor dos Passos n.2 [mudou-se] para a rua do General Pedra n.131 (Jornal do Commercio, 22 jan. 1880).

Em anúncio datado de 11 de dezembro de 1880 no Jornal do Commercio, apesar de um discurso respeitoso às clientes, a viúva Durian não menciona sua qualificação profissional (Jornal do Commercio, 11 dez. 1880). A única menção a ela é nessa publicação de jornal, não aparecendo em nenhum dos livros da Faculdade de Medicina, indicando, em princípio, tratar-se de uma parteira leiga. Nesse ano, já não existiam mais parteiras práticas examinadas pela Fisicatura-Mor.

Ana Candida de Oliveira Godoy, em 1885, anunciava que não era parteira de primeira classe e que também não possuía diploma, porém contava com 24 anos de prática em cuidar de suas amigas e comadres (Souza, 1998). Isso pode demonstrar falhas, ou até mesmo desinteresse, do governo em controlar pessoas sem habilitação para o trabalho na arte de partejar.

Quanto ao Curso de Partos da Faculdade de Medicina, após Durocher se formar, em 1834, só encontramos nova matrícula em 1838, de Maria Victoria Adelaide M. Gonçalves, que foi diplomada em 1839. Posteriormente, matricularam-se Maria Lacosta, 
Felicíssima Rosa Pereira Ferreira, Maria Del Carmen Paiva Brioso, Theresa Jesuina Tygna e Isabel de Moraes e Silva, sendo essas três últimas muito atuantes na arte de partejar na Corte (Cedem, 1838). Diversos foram os seus anúncios no Jornal do Commercio. Brioso publicou anúncios nos dias 5 de junho de 1860, 9 de janeiro de 1865 e 2 de dezembro de 1865, oferecendo seus serviços, não só para a realização de partos, mas também para o tratamento de moléstias do útero: "PARTEIRA - Maria Brioso pode ser procurada na sua residência, rua de $S$. José n.25: dá consulta das 8 às 10 horas da manhã, trata das moléstias do útero e recebe pensionistas" (Jornal do Commercio, 5 jun. 1860).

Tygna foi muito atuante, tendo publicado vários anúncios no Jornal do Commercio nos quais oferecia seus serviços na arte de partejar. Nos dias $1^{\circ}, 9$ e 16 de junho de 1870 , foram publicados anúncios em que ela informa ter mudado para a casa onde morou Mme. Durocher, que era sua amiga pessoal, na rua General Câmara n.113: "A parteira Tygna - fixou a sua residencia na casa que morou a parteira Durocher, rua do General Camara n.113, $1^{\circ}$ andar, onde pode ser procurada a qualquer hora para os misteres de sua profissão. RECADOS POR ESCRIPTO" (Jornal do Commercio, 1 jun. 1870).

Naquele mesmo ano, Isabel deu início à sua vida profissional e, aparentemente, gastou bastante dinheiro com propaganda de seus serviços. Em junho, publicou um anúncio simples informando sua profissão, nacionalidade, endereço e que recebia pensionistas. Nos primeiros dias do mês de dezembro de 1870, investiu bastante em propaganda no Jornal do Commercio, não alterando muito a mensagem do texto. Entre os dias 3 e 9, além das informações fornecidas, acrescentou uma: em relação às pensionistas incluiu a palavra "grávidas": "A PARTEIRA brazileira Isabel de Moraes Silva mora na rua da Imperatriz n.41, sobrado, e aí mesmo recebe pensionistas grávidas" (Jornal do Commercio, 3 dez. 1870).

Geralmente, as parteiras anunciavam, além da prática de partejar, o tratamento de "doenças de senhoras". Mott (2005) observou seis tipos de atividades desempenhadas pelas parteiras em seus anúncios: a) atenção à saúde da mãe e do recém-nascido (gravidez, parto, puerpério e tratamento do umbigo); b) atenção à vida sexual e reprodutiva das mulheres (contracepção, aborto, infertilidade e reconstituição da virgindade); c) tratamento ginecológico ("doenças de senhoras"); d) alojamento e tratamento de parturientes e doentes; e) comerciais (aluguel de ama de leite); e f) "redistribuição" de recém-nascidos, atividade nem sempre dentro da legalidade.

A lei de 3 de outubro de 1832 normatizou que médicos, cirurgiões, boticários e parteiras formados em escolas estrangeiras deveriam prestar o exame de suficiência nas Faculdades de Medicina para poder exercer legalmente suas profissões. Em 24 de abril de 1833, a direção da Faculdade de Medicina mandou oficiar ao governo imperial, que estava convocando, por meio de edital, os indivíduos que curavam, sangravam e partejavam sem título legal, a se apresentar àquela instituição para a realização do exame de suficiência, cujas aprovação e concessão pertenciam à faculdade pelos artigos 13 e 14 da lei de 3 de outubro de 1832 (Cedem, 1831).

Em 12 de setembro de 1834, leu-se um oficio do ministro do Império participando a expedição de ordem às Câmaras Municipais do Império para que não mais consentissem que, em suas localidades, continuassem exercendo as profissões de médico, cirurgião, boticário e parteira pessoas que não mostrassem habilitação de acordo com os termos da 
lei de 3 de outubro de 1832. Com isso, a congregação decidiu elaborar seus estatutos, que, além de determinar os exames que deveriam ser realizados por aqueles que desejassem exercer suas profissões no Império, também determinavam que as parteiras estrangeiras deveriam pagar, a título de honraria, o valor de 25 mil réis, a ser recolhido a um caixa para, ao fim do ano, ser dividido pró-rata entre professores da escola, substitutos e secretários (Cedem, 1831). Entretanto, essa cobrança era indevida por ferir o artigo 14 da lei, o qual estipulava os valores a ser pagos apenas por médicos, cirurgiões e boticários que tivessem seus títulos verificados, não tecendo menção a parteiras.

Apesar disso, os exames de suficiência só começaram a ser cobrados aos estrangeiros, com base na lei de 3 de outubro de 1832, quase cinco anos após a sua promulgação, em 12 de agosto de 1837. Nessa data, observa-se que o primeiro a ser examinado, em conformidade com o artigo 14 da referida lei, foi o cirurgião formado pelo Colégio de Londres, John Duncan, na época com 25 anos de idade, natural da Escócia e filho de Alexandre Duncan (Cedem, 1837).

A primeira parteira estrangeira a ser examinada foi Verônica Pascal, e seu registro de pedido de exame de suficiência é datado de 9 de maio de 1840 (Cedem, 1837). Pelos anúncios que publicou, observa-se que, aparentemente, já possuía bastante experiência, adquirida principalmente na cidade de Buenos Aires, capital argentina, onde partejou por mais de 12 anos. Logo que foi diplomada, começou a publicar anúncios no Jornal do Commercio. No dia 3 de junho daquele mesmo ano, anunciava ser professora de parto, discípula de MDubois pai, recebida pela Maternidade de Paris e Junta Medical de Buenos Aires e que prestava seu serviço em sua residência, na rua da Ajuda n.55 (Jornal do Commercio, 3 jun. 1840). Publicou anúncios durante todo o ano, sendo o último no dia 5 de dezembro (Jornal do Commercio, 5 dez. 1840). Entretanto, parece não ter tido vida longa no mercado, uma vez que cinco anos depois já não se encontravam mais seus anúncios no jornal.

Quatro anos após o assentamento de Pascal no Livro de termos de exames de verificação de médicos, cirurgiões, boticários e parteiras, Felícia Hosxe fez sua solicitação, sendo aprovada no exame de suficiência. As próximas parteiras encontradas foram Clementina Pereira Sonjean, ${ }^{11}$ M. Gault, ${ }^{12}$ Felícia Hautefeuille, Joanne Beau, Theresa Magdaleine Pondville, Joanna Louisa Langlois, Elisabeth Servais, Catharina Augustine Prochet, Maria Paulina Page Daux, Maria P. Deany (aparentemente reprovada), Catharina Mosser (reprovada), Maria Reischeid, Marie Cesarine Charneroy, Victoria Borget, Luigia Vedosa, Carolina Rosa Mériel, Catharina Cacluvan Bérenguer, Pauline Moitrel, Paulina Eugenia Henriques, Marie Angelique Hortense Vernot e, a última encontrada no livro, Adele Genoveve Chabrial, examinada e aprovada em 3 de janeiro de 1863. Nos livros de atas da congregação, aparecem ainda as parteiras Helena Augusta Pinto Meirelles, Maria Danjean, uruguaia que não teve seu título reconhecido, Catharina Hemminger, Natalia Migoni de Messo, Isabel Pellisier e Cecilia Jacobsen. Esta última não realizou o exame por não haver nenhum tradutor de dinamarquês (Cedem, 1837).

Se na pesquisa nos livros oficiais do Centro de Documentação do Ensino Médico, a última parteira apareceu em 1881 (Cedem, 1880), não se pode dizer o mesmo das publicações de serviços de parteiras no Jornal do Commercio. Muitas aparecem oferecendo suas habilidades na arte de partejar, entretanto, não tendo sido encontradas nos registros da Faculdade de 
Medicina, não sabemos se eram legalizadas ou não. Algumas informaram ser formadas em escolas estrangeiras, porém não demonstraram ter sido examinadas pela Faculdade de Medicina do Rio de Janeiro. É o caso de Anna Chevalier, Catharina Cadiron, Pou Arnold, Mme. Costel, Mme. Pourtois, ${ }^{13}$ Pauline Napoléon Gaullier, Mme. Daure - proprietária de uma maternidade -, Mme. Profillet, Mme. Bardeaud, Mme. Leopold, Justina Hollingier de Souza, Mme. Marguerite, Mme. Léonie Barros, Mme. Camille Pucheu, Mme. Asty, Mme. Anna Stettler, Mme. Murillo, Mme. Massou, Maria Driebacher, Mme. Delcher e Mme. Desiderate. Das parteiras encontradas nos livros da Faculdade de Medicina, poucas foram localizadas nos anúncios do Jornal do Commercio.

\section{A concorrência pela "arte de partejar" nas propagandas do Jornal do Commercio}

Ao se comparar o número de parteiras com o de médicos que anunciavam propagandas, observa-se uma diferença exorbitante, no que diz respeito tanto ao número de anúncios publicados como ao tamanho das propagandas. Ambos os motivos demonstram claramente a diferença social entre os dois segmentos profissionais. Poucas foram as parteiras com condições financeiras suficientes para publicar anúncios, e muito menos ainda foram aquelas que podiam publicá-los em tamanhos razoáveis na coluna "Anúncios" do Jornal do Commercio.

Geralmente, as que possuíam mais recursos para tal eram aquelas formadas em escolas estrangeiras que aqui aportavam a fim de tentar melhor sorte que em seus países de origem. Nesse caso, pode-se destacar Felicia de Hautefeuille, Clementina Sonjean, Mme. Bérenger, Mme. Marguerite e Felícia Hosxe. Entre as parteiras formadas pela Faculdade de Medicina do Rio de Janeiro, estão Mme. Durocher e Maria Del Carmem Paiva Brioso, mais conhecida como Mme. Brioso. Outras parteiras, cuja formação é desconhecida, também apareciam constantemente nos anúncios do Jornal do Commercio, tais como Mme. Daure - na propaganda de sua Maternidade São Vicente de Paula - e Mme. Justina Hollingier de Souza.

Com relação aos médicos, acontecia o contrário. Raros eram aqueles que não tinham posses. Muitos dos que publicaram anúncios no Jornal do Commercio eram políticos ou filhos de políticos importantes e influentes, como é o caso do doutor Carneiro Leão, o barão do Paraná, do doutor Luís da Cunha Feijó, o visconde de Santa Isabel, e do doutor Souza Fontes, o visconde de Souza Fontes. Alguns chegavam a publicar diversas propagandas no mesmo dia na coluna "Anúncios", como o doutor Vieira Souto.

Entretanto, não se pode generalizar as condições financeiras das parteiras. Algumas, aparentemente, possuíam recursos que lhes garantiam certa igualdade na concorrência com os médicos na arte de partejar. Toma-se como exemplo os casos de Mme. Daure, Mme. Asty, Mme. Bérenger e Mme. Marguerite. Daure era proprietária de uma maternidade, e seu estabelecimento contratava médicos, como o doutor José Maurício Nunes Garcia - lente da Faculdade de Medicina - e o doutor Belmonte de Andrade. Também proprietária de uma maternidade, Marguerite contratava médicos para atuar como internos. Em 1876, o doutor José Ferreira Barreto passa a trabalhar como médico-interno da instituição. No ano seguinte, junta-se a ele o doutor João Pizarro Gabiso, lente da Faculdade de Medicina, e, em 1878, o doutor Macedo Soares (Souza, 1998). 
Marguerite, Asty e Bérenger também se destacaram por serem donas de linhas telefônicas, certamente um luxo não compatível com os recursos financeiros da maior parte das parteiras da época. Para se ter uma ideia, em janeiro de 1885, Mme. Marguerite anunciou dois números de linhas telefônicas diferentes, 383 nos dias 4 e 18, e 913 no dia 25. Mme. Asty, no dia 11 do mesmo período, anunciava a linha telefônica de número 469, e, em 4 de junho do mesmo ano, Mme. Bérenger informava que o número de sua linha telefônica era 1.551 (Jornal do Commercio, 4 jan. 1885). De qualquer forma, a realidade financeira dessas parteiras era totalmente diferente das demais, inclusive da mais célebre, Mme. Durocher, que, de acordo com a presente pesquisa, nunca informou em suas propagandas qualquer número de linha telefônica e nunca se fixou em apenas um local.

Só a título de comparação, poucos foram os médicos que informaram números de linha telefônica, o que pode demonstrar o alto custo do investimento ou, no máximo, um certo conservadorismo por parte de alguns. De qualquer forma, em 20 janeiro de 1885, o doutor José Rodrigues dos Santos informava que poderia ser procurado no número 1.507. Já o doutor Souza Fontes, em 2 de dezembro do mesmo ano, publicava que poderia ser contatado pelo telefone de número 5.068. Em $1^{\circ}$ de junho de 1890, o doutor Camargo comunicava que atendia a chamados no número 357, e, em 23 de junho do mesmo ano, o doutor Rego Monteiro atendia no número 1.902. Por fim, em $1^{\circ}$ de janeiro de 1895 , o doutor Vieira Souto atendia a chamados no número 1.138, e o doutor Martins Ribeiro, em 6 de janeiro daquele ano, publicou que atendia nos números 357 e 5.205, ou seja, duas linhas telefônicas, o que demonstra que possuía boas condições financeiras (Jornal do Commercio, 20 jan. 1885, 2 dez. 1885, 1 jun. 1890, 23 jun. 1890, 1 jan. 1895, 6 jan. 1895).

Entre 1835 e 1850, foram encontradas dez propagandas de parteiras e nenhuma de médicos. Em 1855, apenas um médico publicou seus serviços, enquanto três parteiras ofereciam seus "misteres" na arte. Em 1860, começa a inversão dessa estatística: quatro parteiras oferecendo serviços contra nove médicos, porém, em 1865, o número de parteiras aumentou para seis, enquanto o de médicos caiu para apenas cinco. De acordo com Santos Filho (1947), nesse período, acadêmicos de medicina, médicos e professores das Faculdades de Medicina do Rio de Janeiro e da Bahia prestaram serviços médicos e cirúrgicos às forças em operação na Guerra do Paraguai.

Em 1870, voltaram a ser oito os médicos-parteiros anunciando serviços, enquanto o número de parteiras se manteve estável em cinco. Os anos de 1865 e 1870 foram os únicos em que houve relativo equilíbrio entre o número de parteiras e de médicos que ofereciam seus serviços. Novo aumento verificou-se em 1875, em ambos os segmentos, passando a oito o número de parteiras que publicaram propagandas e 15 o número de médicos. Em 1880, o número de parteiras manteve-se estável em sete, enquanto o número de médicos caiu para dois. Em 1885, foram 27 médicos-parteiros e oito parteiras que publicaram propagandas. Em 1890, esses números caíram para vinte médicos e apenas duas parteiras. Em 1895, passaram a ser 23 médicos contra apenas três parteiras, e esse número alcançou o ápice em 1900, chegando a 43 médicos contra apenas três parteiras que publicaram seus serviços (ver Tabela 1). 
Tabela 1: Quantidade de parteiras e médicos anunciados no Jornal do Commercio por ano e área da cidade do Rio de Janeiro, 1835 a 1900

\begin{tabular}{|c|c|c|c|c|c|c|c|c|c|c|}
\hline \multirow{3}{*}{ ANO } & \multicolumn{5}{|c|}{ PARTEIRAS } & \multicolumn{5}{|c|}{ MÉDICOS } \\
\hline & \multicolumn{4}{|c|}{ ÁREAS } & \multirow[b]{2}{*}{ Total } & \multicolumn{4}{|c|}{ ÁREAS } & \multirow[b]{2}{*}{ Total } \\
\hline & 1 & 2 & 3 & 4 & & 1 & 2 & 3 & 4 & \\
\hline 1835 & - & 2 & - & - & 2 & - & - & - & - & 0 \\
\hline 1840 & 1 & - & - & - & 1 & - & - & - & - & 0 \\
\hline 1845 & - & 3 & - & - & 3 & - & - & - & - & 0 \\
\hline 1850 & - & 3 & - & 1 & 4 & - & - & - & - & 0 \\
\hline 1855 & 1 & 1 & - & 1 & 3 & - & 1 & - & - & 1 \\
\hline 1860 & 1 & 2 & - & 1 & 4 & 2 & 4 & 1 & 2 & 9 \\
\hline 1865 & 3 & 3 & - & - & 6 & 1 & 4 & - & - & 5 \\
\hline 1870 & - & 5 & - & - & 5 & 2 & 4 & - & 2 & 8 \\
\hline 1875 & 3 & 4 & - & 1 & 8 & 2 & 8 & 2 & 3 & 15 \\
\hline 1880 & 2 & 4 & - & 1 & 7 & - & 2 & - & - & 2 \\
\hline 1885 & 1 & 4 & - & 3 & 8 & 5 & 15 & 2 & 5 & 27 \\
\hline 1890 & 1 & 1 & - & - & 2 & 4 & 12 & - & 4 & 20 \\
\hline 1895 & 1 & 1 & - & 1 & 3 & 4 & 11 & 2 & 6 & 23 \\
\hline 1900 & 2 & 1 & - & - & 3 & 8 & 20 & 4 & 11 & 43 \\
\hline
\end{tabular}

Fonte: Jornal do Commercio, de 1835 a 1900.

Nessa pesquisa, nota-se que os médicos buscavam ter as senhoras da sociedade como clientes, enquanto as parteiras, a partir da década de 1870, visavam às pensionistas como freguesas. Ao ser paulatinamente alijadas do mercado tradicional, parecem ter vislumbrado nas pensionistas um potencial regular de serviços.

Segundo Mott, as pensionistas eram as parturientes (Souza, 1998). No entanto, levantamos a hipótese de que, podendo ser parturientes ou não, o significado de pensionistas era mais amplo: eram mulheres que trabalhavam por conta própria em diversos serviços e atividades na Corte e que não tinham moradia fixa na cidade. Essas mulheres buscavam nas parteiras os diversos serviços oferecidos por elas, como o parto e o tratamento de "doenças de senhoras", por exemplo. Em anúncios voltados para as pensionistas no Jornal do Commercio dos dias 27 e 30 de junho de 1865, estas são convocadas para participar de mesas-redondas, jantares para fora e soirées em casa de particulares. Parece pouco provável que esses anúncios fossem destinados a parturientes.

PENSIONISTAS. Tomam-se pensionistas para mesa redonda, assim como também jantares para fora, por preços cômodos, e encarrega-se de encomendas, na rua do Hospicio n.1, $1^{\circ}$ andar (Jornal do Commercio, 27 jun. 1865).

MESA REDONDA. Recebem-se pensionistas por preço razoável, manda-se para casas de comércio, assim como se encarrega de aprontar qualquer soirée em casa particular, trata-se na rua do Rosario n.50, $2^{\circ}$ andar (Jornal do Commercio, 30 jun. 1865). 
Assim, acredita-se que pensionistas constituíam uma categoria ampla de mulheres sem residência fixa na cidade e que trabalhavam nas mesmas atividades das mulheres residentes - que geralmente labutavam para aumentar suas rendas familiares - mas que moravam em pensões, imóveis localizados, geralmente, em áreas populares.

O discurso médico traduzia a imagem da sociedade patriarcal brasileira. ${ }^{14}$ É nesse sentido que essas mulheres, que trabalhavam para aumentar a renda de suas famílias, aproximavam-se das parteiras, pois também laboravam na mesma situação. Contudo, ficase o questionamento: as prostitutas também seriam clientes em potencial das parteiras? Acredita-se que sim, pois muitas parteiras possuíam domicílio e atendiam próximo a áreas de prostituição.

A cidade do Rio de Janeiro era dividida em freguesias de dentro e de fora. As de dentro ficavam nos limites territoriais do que hoje é o Centro da cidade, as de fora, o sertão, incluíam fazendas e engenhos e foram sendo ocupadas paulatinamente. Com o advento da linha férrea, foram se formando os bairros do subúrbio. As freguesias de dentro eram cinco: (a) Santana - ocupava as terras do campo da Aclamação e, para além, a atual praça Onze e a Cidade Nova, fazendo limite com Estácio e Rio Comprido, os morros da Providência e do Livramento, a Gamboa e o Saco de São Diogo (atual zona portuária, avenida Francisco Bicalho, Leopoldina e Rodoviária); (b) Santa Rita - ocupava o espaço entre o morro da Conceição, morro de São Bento e largo de Santa Rita, tendo as ruas Estreita e Larga de São Joaquim (atual avenida Marechal Floriano) como limite com a freguesia do Sacramento e da Candelária; (c) Candelária - ocupava o espaço entre o mar, as ruas Estreita e Larga de São Joaquim, a rua da Quitanda até a rua São José; (d) Sacramento - ocupava o espaço entre o campo da Aclamação, a rua do Conde do Cunha (atual Visconde do Rio Branco), rua dos Piolhos (atual rua da Carioca), rua São José, rua da Quitanda e as ruas Estreita e Larga de São Joaquim e; (e) São José - ocupava o espaço entre a rua São José, rua dos Piolhos, rua do Conde do Cunha, rua Nova de São Lourenço (atual rua dos Inválidos), rua de Matacavalos (atual rua do Riachuelo), avenida Mem de Sá e rua da Lapa.

A freguesia da Glória, que ocupava os espaços dos atuais bairros da Glória, Catete, Santa Teresa, largo do Machado, Laranjeiras, Flamengo e Botafogo, era considerada uma freguesia de fora, servindo como local de veraneio. Porém, com a implantação dos serviços de diligências e o incremento da navegação a vapor pela baía de Guanabara, rapidamente começou a ser habitada. Contudo, o mapa anexo foi dividido em quatro áreas, de acordo com o número de anúncios no Jornal do Commercio, por vezes dividindo, por vezes incorporando freguesias (ver Figura 1).

Segundo Lassance Cunha, em tese para a Faculdade de Medicina no ano de 1845, a prostituição estava disseminada por toda a Corte, mas se concentrava em um espaço geográfico limitado pelo atual campo de Santana, avenida Presidente Vargas, rua Buenos Aires e rua Uruguaiana, hoje ocupado pela região do Saara e pelo Mercado Popular da Uruguaiana, vulgarmente conhecido como Camelódromo. Quanto às prostitutas mais pobres, estavam espalhadas, habitando casebres nas ruas dos Ferradores - atual Alfândega (em seu final) -, do Sabão e de São Pedro - extintas para a construção da avenida Presidente Vargas - e do Hospício - atual Buenos Aires (citado em Silva, 2012a). 


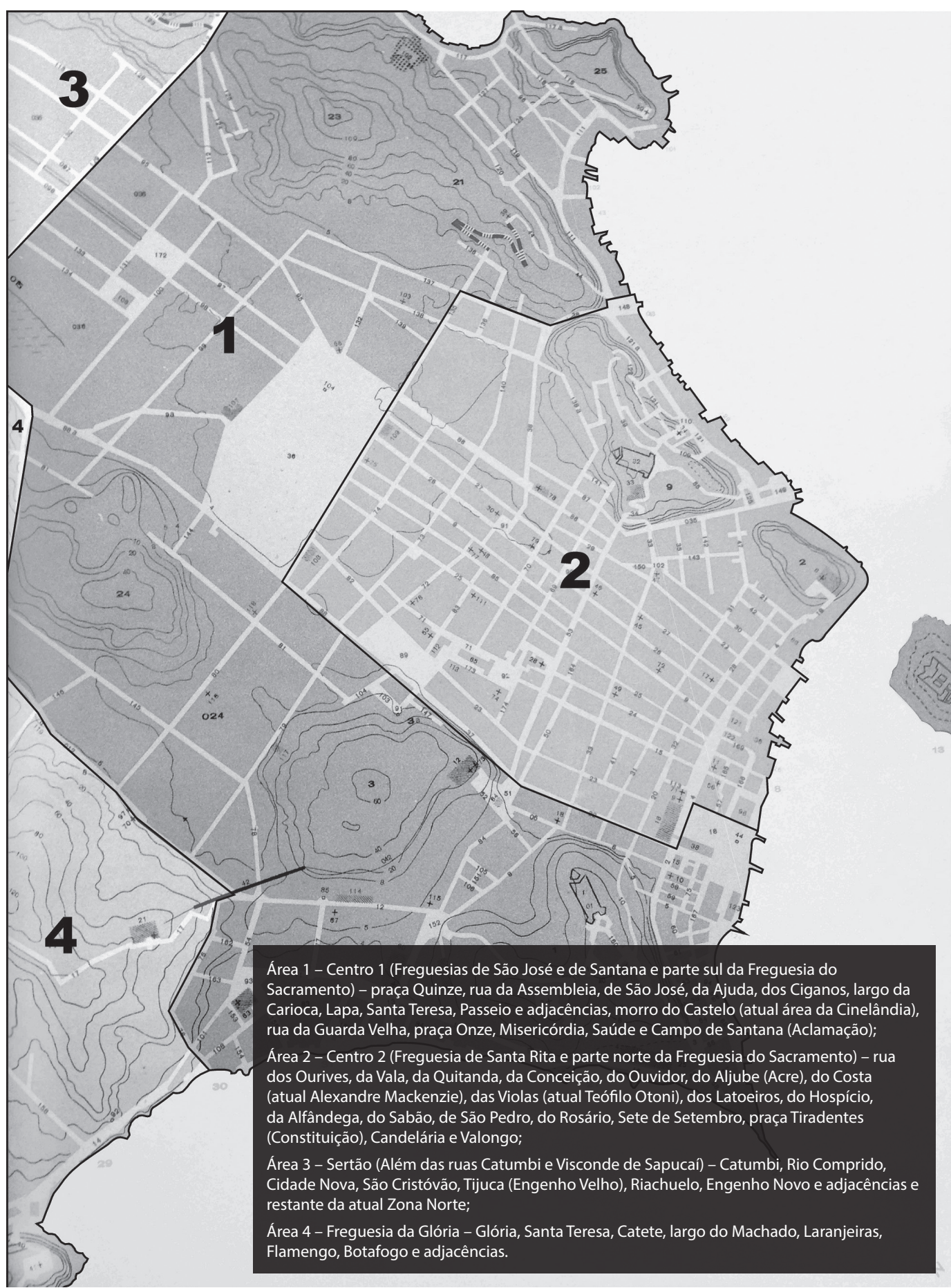

Figura 1: "A cidade do Rio de Janeiro nos meados do século XIX, baseada na Planta Garnier de 1852" (Fonte: Barreiros, 1965) 
Pelas localizações informadas nas propagandas publicadas no Jornal do Commercio, várias foram as parteiras que trabalharam nessa área: Clementina Rosa do Rego, em 1850; Mme. Carolina Hériel, em 1860; Mme. Vitória Borget, em 1865; Tygna e Mme. Durocher, em 1870; e Mme. Justina Hollingier de Souza, em 1885.

Clementina Sonjean, desde o princípio, pareceu demonstrar não ter tido preconceitos com a clientela, uma vez que recebia suas clientes na rua da Vala, atual Uruguaiana. Não se pode afirmar quem eram suas principais clientes, entretanto instalou-se no limite da área de maior número de prostitutas da cidade. Em 1850, por algum motivo desconhecido, já havia mudado de endereço, passando a residir e partejar na freguesia da Glória, próximo ao largo do Machado, onde atendia suas clientes na rua Carvalho de Sá. Cinco anos depois, morava e partejava na rua das Laranjeiras, n.2, também próximo ao largo do Machado.

Se Sonjean partejou por aquelas bandas, então pouco habitadas, por pioneirismo, não se sabe. A presença de uma parteira estrangeira examinada pela Faculdade de Medicina do Rio de Janeiro por aquelas paragens um tanto quanto inóspitas pode ter sido um alento às parturientes da alta sociedade local, carentes daquele serviço. Contudo, a freguesia da Glória começava a se destacar por abrigar casas de entretenimento e prostituição. Segundo Engel (2004), a prostituição durante a segunda metade do século XIX estava localizada nas mais diversas regiões da Corte. Só o largo do Machado abrigava dois music halls: $:^{15} \mathrm{O}$ "Cassino" e o "Parque Fluminense" (Engel, 2004).

No entanto, as primeiras parteiras encontradas na pesquisa, principalmente as diplomadas, visavam ter como clientes as senhoras da alta sociedade carioca. Mme. Stephanie atendia no início da rua da Alfândega; Felicia de Hautefeuille, na rua dos Ourives e, anos depois, na rua do Rosário; e Anna Chevalier partejava na rua da Quitanda, mudando-se posteriormente para a rua do Ouvidor. Em 1850, Catharina Cadiron, assim como Chevalier anos antes, partejava na rua da Quitanda; e Clementina Rosa do Rego, no início da rua da Alfândega, locais de moradia mais valorizadas e de comércio de luxo na Corte.

Tal situação mudou paulatinamente após a entrada dos médicos-parteiros no mercado, principalmente durante a década de 1870, com a divulgação das Conferências da Glória. As parteiras começaram a vislumbrar as pensionistas como um mercado em potencial. A maioria dos anúncios de parteiras citava as ruas Gonçalves Dias, Alfândega e Guarda Velha - atual Treze de Maio - como seus locais de residência e trabalho (ver Tabela 2). A Gonçalves Dias, um ponto de glamour na cidade, abrigava logradouros famosos na época, como a Rotisseria Americana, o Café Papagaio e a Confeitaria Colombo, famosa até os dias atuais. Nesse estabelecimento, a frequência dividia-se em dois horários observados com rigor: entre 14 e 17 horas, o público era constituído pelas "senhoras de família" e a partir das 17h30min começava a ser frequentado por prostitutas (Engel, 2004). Próximo à rua do Rosário, havia um hotel voltado para a prostituição de luxo, uma pension d'artistes, que Brasil Gerson comenta de forma sucinta:

Rua que no final do século passado [século XIX] já fazia certa sombra a do Ouvidor; que tinha o cabeleireiro Schmidt, das damas do Paço Imperial, para atrair as mulheres elegantes; e a farmácia de Teixeira Novaes, das primeiras do Rio a popularizarem a homeopatia; e os sorvetes da Casa Dô, quando tão poucas eram as que serviam entre nós ainda; e que tinha ainda para os lados do Rosário algo já de outro gênero, o que 
se chamava uma casa de prazeres noturnos à moda parisiense, o 'Palácio de Cristal' (Gerson, 2000; destaque no original).

Aparentemente não era qualquer parteira que conseguiria instalar-se em um consultório em rua tão valorizada na cidade, somente aquelas com condições financeiras suficientes para manter-se no local. As duas únicas encontradas em propagandas que partejaram naquela rua foram Mme. Bérenger, em 1860, e Mme. Marguerite, em 1870, e posteriormente, entre 1880 e 1885. Como já visto anteriormente, ambas possuíam bens aos quais a maioria não tinha acesso e, pelo padrão de seus consultórios, certamente, disputavam com os médicos a clientela composta pelas senhoras da alta sociedade, porém, com o sucesso do discurso científico das Conferências da Glória, possivelmente passaram a visar como clientes às dançarinas do Palácio de Cristal.

Tabela 2: Localidades mais anunciadas pelas parteiras

\begin{tabular}{l|c}
\hline \multicolumn{1}{c|}{ ENDEREÇOS } & QUANTIDADE \\
\hline Rua Gonçalves Dias/Latoeiros & 9 \\
\hline Rua da Alfândega & 7 \\
Rua da Guarda Velha & 5 \\
Rua da Imperatriz & 4 \\
Rua da Ajuda & 4 \\
Rua das Laranjeiras & 4 \\
\hline
\end{tabular}

Fonte: Jornal do Commercio, de 1835 a 1900.

A rua da Guarda Velha abrigava um music hall chamado Guarda Velha. Brasil Gerson comenta que o Guarda Velha era uma cervejaria, uma das primeiras que no Rio existiram, e que ao seu lado havia um parque, local onde, além de se beber cerveja, dançava-se e assistia-se a espetáculos de café-concerto. Posteriormente, em 1886, tal estabelecimento mudou-se para a rua Senador Dantas, e no local por ela primitivamente ocupado apareceram a estação dos bondes, popularizada como Tabuleiro da Baiana e o edifício do Liceu Literário Português (Gerson, 2000). Partejaram por lá Mme. Brioso, em 1860; Vitória Borget, em 1865; e Mme. Marguerite, em 1875.

Por fim, os médicos estavam mais concentrados na freguesia do Sacramento, e as ruas mencionadas com maior frequência nos anúncios foram Ourives, Quitanda e Rosário (ver Tabela 3), pontos de comércio de luxo e moradia da alta sociedade no Centro da cidade, indicando sua preferência pelas senhoras da alta sociedade como clientes, como já foi visto. Aparentemente, no entanto, os médicos tinham uma clientela diversa. O doutor Vieira Souto possuía consultório na praça Tiradentes e ali atendeu por longo período. Certamente, não teve apenas senhoras da sociedade como clientes antes de trasladar-se para a rua Primeiro de Março e para a Praia de Botafogo. Seu consultório foi, ocupado, mais tarde, pela parteira Mme. Desiderate. Os anúncios de parteiras no Jornal do Commercio, contudo, foram se tornando gradativamente escassos no final do século XIX. 
Tabela 3: Localidades mais anunciadas pelos médicos

\begin{tabular}{|l|c|}
\hline \multicolumn{1}{|c|}{ ENDEREÇOS } & QUANTIDADE \\
\hline Rua dos Ourives & 28 \\
\hline Rua da Quitanda & 16 \\
\hline Rua do Rosário & 11 \\
\hline Rua São Pedro & 11 \\
\hline Praça Tiradentes & 9 \\
\hline Rua do Hospício & 8 \\
\hline Rua do Carmo & 8 \\
\hline Rua Primeiro de Março & 8 \\
\hline
\end{tabular}

Fonte: Jornal do Commercio, de 1835 a 1900.

Concluindo o presente trabalho, acredita-se que, até a década de 1870, o domínio da arte de partejar na Corte estava praticamente nas mãos das parteiras, passando paulatinamente para as mãos dos médicos a partir de meados dessa década. Os fatores que contribuíram para isso foram os discursos científicos promovidos por intelectuais nas Conferências da Glória na década de 1870 e a criação das cadeiras de obstetrícia e ginecologia nas duas faculdades de medicina brasileiras, com a Reforma do Ensino Médico de 1879. Ambos contribuíram para consolidar o discurso médico e sua cientificidade nessa área de atuação junto à sociedade, acarretando uma intensificação da ação médica na disputa pelo espaço na arte de partejar feita com argumentos pautados na ciência.

Apesar de poucas parteiras, como Mme. Bérenger e Mme. Marguerite, terem conseguido obter algum sucesso nessa concorrência com os médicos pelas clientes da alta sociedade, dispondo de maternidades e consultórios bem equipados, até com linhas telefônicas, um luxo caro para a época, não foram capazes de superar a propaganda científica de medicalização do parto. Com isso, buscaram ter as pensionistas como clientes em potencial.

\section{NOTAS}

${ }^{1}$ Devido ao longo espaço temporal a analisar, definiu-se realizar o levantamento dos meses de janeiro, junho e dezembro, por serem os meses do início, meio e fim dos anos, com intervalo de pesquisa de cinco anos. Os anos pesquisados no Jornal do Commercio foram 1831 - ano da abertura do Livro de Atas da Congregação da Faculdade de Medicina, portanto, o ano inicial da pesquisa -, 1835, 1840, 1845, $1850,1855,1860,1865,1870,1875,1880,1885,1890,1895$ e 1900. Os primeiros anúncios de parteiras apareceram em 1935.

${ }^{2}$ Mott, (2005, p.119) afirma que a palavra "comadre" demonstra afetividade e respeito, evidência do vínculo entre quem assiste [ao parto] e quem é assistida. Essas comadres poderiam ser parteiras "ocasionais", que realizavam alguns partos ao longo da vida, ou "de ofício", que, apesar de leigas, tinham larga experiência e capacidade para resolver partos considerados difíceis nos dias atuais.

${ }^{3}$ José Francisco Xavier Sigaud nasceu em Marselha (França), em 2 de dezembro de 1796. Chegou ao Brasil em 1825 e em 1829, juntamente com Joaquim Cândido Soares de Meirelles, José Martins da Cruz Jobim, Luís Vicente De Simoni e Jean Maurice Faivre, fundou a Sociedade de Medicina do Rio de Janeiro, da qual foi presidente em 1830, 1832, 1851 e 1852. Publicou artigos e livros sobre a saúde no Brasil. Seu livro mais conhecido é Sobre o clima e as doenças no Brasil, editado na França em 1844, o que lhe valeu, naquele mesmo ano, a condecoração da Cruz da Ordem Real da Legião de Honra pelo rei da França, Louis Philippe I, e o título de Cavaleiro da Ordem Imperial do Cruzeiro, concedido pelo imperador dom Pedro II. Naturalizouse brasileiro em 1854. Participou da criação do Imperial Instituto dos Meninos Cegos (atual Instituto 
Benjamin Constant), estabelecido pelo decreto n.1.428, de 12 de setembro de 1854, tendo sido seu diretor até sua morte, no Rio de Janeiro, em 10 de outubro de 1856 (Sigaud..., s.d.).

${ }^{4} \mathrm{O}$ doutor Rodrigo Soares Cid de Bivar foi aprovado no exame de suficiência na Faculdade de Medicina do Rio de Janeiro no dia 20 de novembro de 1847. A ata do exame não informa em qual escola de medicina estrangeira se titulou o referido médico (Medeiros, 2015, p.269).

${ }^{5}$ Não só a reprodução e a sexualidade eram temas recorrentes entre os médicos, como também o aleitamento e o aborto. Em 1879, o médico higienista Carlos Costa fundou, na cidade do Rio de Janeiro, o jornal $A$ Mãe de Família, onde eram publicadas matérias relativas à higiene infantil, sendo seu público-alvo a mulher branca da elite. As matérias defendiam o aleitamento materno e condenavam a amamentação realizada por amas de leite (Carula, 2012, p.198).

${ }^{6}$ Em relação ao aborto, realizou-se pesquisa, na Base Minerva da Universidade Federal do Rio de Janeiro, de teses produzidas nas Faculdades de Medicina da Bahia e do Rio de Janeiro entre 1840 e 1900 sobre o assunto. Foram encontradas 143 teses relacionadas ao tema cujos assuntos tratados diziam respeito ao aborto espontâneo, terapêutico, criminoso e ao tratamento pós-cirúrgico. Marinete Silva, que também realizou levantamento dessas teses, observou que havia um acompanhamento dos debates sobre o assunto nas capitais europeias, sobretudo na França; e uma evolução do foco de interesse, das técnicas de interrupção da gravidez - o chamado aborto terapêutico - para a preocupação com o aborto criminoso, praticado clandestinamente por parteiras e curiosas ou pelas próprias interessadas, segundo seus autores (Silva, 2012b, p.1242, 1243).

${ }^{7}$ Rohden (2001, p.22) comenta que o ponto central do debate se fixava no fato de que o controle da natalidade e, principalmente, o aborto e a contracepção passaram a ser discutidos não apenas em função das consequências para os indivíduos que os praticavam, mas em relação ao que implicava em termos de ameaça ao crescimento da nação, e tal panorama ficaria mais complexo, uma vez que a questão da população começava a ser pensada a partir da eugenia.

${ }^{8}$ Cargo extinto pela lei de 30 de agosto de 1828.

${ }^{9}$ Mott (2005, p.119) comenta que, segundo relatos de viajantes e da própria Mme. Durocher, uma forma de as parteiras leigas divulgarem seus serviços era colocando uma cruz branca na porta das casas. Com o advento das parteiras diplomadas, algumas dessas profissionais passaram a divulgar seus serviços distribuindo folhetos de propaganda nas ruas, o que, aparentemente, prevaleceu por todo o século.

${ }^{10}$ Nascida na cidade de Beauvois, França, em 11 de maio de 1806, Stephanie Marie Françoise Wernault formou-se sage femme pela Faculdade de Medicina de Paris em 1825. Aqui chegando, teve seu diploma registrado na Câmara Municipal do Rio de Janeiro e, em 1830, foi admitida como parteira da Santa Casa da Misericórdia por intervenção do imperador dom Pedro I. No mesmo ano publicou, em português, um livro de instrução de parteiras e, em 1864, ainda publicava anúncios oferecendo seus serviços. Mme. Durocher teceu-lhe comentários elogiosos, afirmando ser bastante inteligente e possuidora de precisa instrução, já que escrevia ortograficamente, coisa que poucas faziam (Souza, 1998, p.54, 206).

${ }^{11}$ Segundo Maria Lucia Mott (2005, p.118), Sonjean, além de trabalhar na Corte, trabalhou em Recife e, além de partejar, vacinava, sangrava, alugava, vendia amas de leite e oferecia crianças para criar, conforme anúncios por ela publicados. Contudo, a autora não encontrou anúncios de Sonjean oferecendo esses tipos de serviços.

${ }^{12}$ Em anúncio no Jornal do Commercio, de 13 de março de 1844, dizia ser mestra parteira e discípula da Maternidade de Paris (Mott, 2005, p.124).

${ }^{13}$ Em 1849, Louise Berghchmont, seu nome verdadeiro, informava ser professora de parto (Mott, 2005, p.124).

${ }^{14}$ A mulher trabalhadora, naqueles tempos, era vista como desonesta pelos médicos. Nos discursos médicos, a prostituição era considerada uma atividade remunerada ilegítima, inserida na categoria da desordem social. As prostitutas clandestinas eram definidas como aquelas que exerciam ocultamente a prostituição sob a capa de atividades tais como costureira, florista, parteira, lavadeira, enfermeira, pintora, modista, entre outras. As noções de trabalho e de honestidade eram exclusivamente qualificadoras da profissão ou ofício utilizado como disfarce. Mulher honesta só poderia ser a esposa/mãe (Engel, 2004, p.94-95).

${ }^{15}$ Brasil Gerson concorda com Engel ao afirmar que esse era o termo utilizado na época para a cervejaria Guarda Velha, na atual rua Treze de Maio (Gerson, 2000, p.102). 


\section{REFERÊNCIAS}

AGE, Mônica de Paula P. da Silva.

Medicina erudita no hospital real militar da capitania de Goiás, 1800-1825. Disponível em: http://www.snh2011.anpuh.org/resources/ anais/14/1300133412_ARQUIVO_MONICA AGEdoc.MedicinaeruditanoHospitalRealMilitar daCapitaniadeGoias.pdf. Acesso em: 8 out. 2015. 2011.

BARREIROS, Eduardo Canabrava. Atlas da evolução urbana da cidade do Rio de Janeiro. Rio de Janeiro: IHGB. 1965.

BRASIL.

Câmara do Deputados. Lei de 3 de outubro de 1832. Disponível em: http://www2.camara. leg.br/legin/fed/ lei_sn/1824-1899/lei-37274-3outubro-1832-563716-publicacaooriginal-87775pl.html. Acesso em: 11 maio 2014. 1832.

BRENES, Anayansi Correa.

História da parturição no Brasil, século XIX. Cadernos de Saúde Pública, v.7, n.2, p.135-149. 1991.

CARULA, Karoline.

Perigosas amas de leite: aleitamento materno, ciência e escravidão em A Mãe de Família. História, Ciências, Saúde - Manguinhos, v.19, supl., p.197-214. 2012.

CARULA, Karoline.

As conferências populares da Glória e as discussões do darwinismo na imprensa carioca (1873-

1880). Dissertação (Mestrado em História) Universidade Estadual de Campinas, Campinas. 2007.

\section{CEDEM.}

Centro de Estudos do Ensino Médico. Livro de Ata de 1880. Livro de Ata da Congregação da Faculdade Nacional de Medicina: 1880-1883. (Arquivo CCS/UFRJ, Rio de Janeiro). 1880.

\section{CEDEM.}

Centro de Estudos do Ensino Médico. Livro do curso de partos de 1838. Livro de matrículas no Curso Particular de Partos. (Arquivo CCS/UFRJ, Rio de Janeiro). 1838.

\section{CEDEM.}

Centro de Estudos do Ensino Médico. Livro de termos de exames de verificação de 1837. Livro de termos de exames de verificação de médicos, cirurgiões, boticários e parteiras. (Arquivo CCS/ UFRJ, Rio de Janeiro). 1837.

\section{CEDEM.}

Centro de Estudos do Ensino Médico. Livro de Ata de 1831. Livro de Ata da Congregação da Faculdade Nacional de Medicina: 1831-1839. (Arquivo CCS/UFRJ, Rio de Janeiro). 1831.
CREMERJ.

Conselho Regional de Medicina do Estado do Rio de Janeiro. Resolução n.265, de 13 de julho de 2012. Disponível: http://old.cremerj.org.br/ legislacao/detalhes.php?id=764\&item $=1$. Acesso em: 12 maio 2014. 2012.

ENGEL, Magali.

Meretrizes e doutores: saber médico e prostituição no Rio de Janeiro (1840-1890). São Paulo: Brasiliense. 2004.

GERSON, Brasil.

História das ruas do Rio: e da sua liderança na história política do Brasil. Rio de Janeiro: Lacerda. 2000.

JANNUZZI JR., Fernando A.J.

Família Fortes de Bustamante. Carta Mensal: Colégio Brasileiro de Genealogia, ano 15, n.67. Disponível em: http://www.cbg.org.br/ cartamensal/CM67.pdf. Acesso em: 8 out. 2015. 2002.

JORNAL DO COMMERCIO.

[Rio de Janeiro]. Coluna Anúncios, v.80, n.174, p.7. 24 jun. 1900.

JORNAL DO COMMERCIO.

[Rio de Janeiro]. Coluna Indicações Úteis, v.73, n.6, p.6. 6 jan. 1895.

JORNAL DO COMMERCIO.

[Rio de Janeiro]. Coluna Indicações Úteis, v.73, n.1, p.5. 1 jan. 1895.

JORNAL DO COMMERCIO.

[Rio de Janeiro]. Coluna Indicações Úteis, v.68, n.174, p.4. 23 jun. 1890.

JORNAL DO COMMERCIO.

[Rio de Janeiro]. Coluna Indicações Úteis, v.68, n.152, p. 2.1 jun. 1890.

JORNAL DO COMMERCIO.

[Rio de Janeiro]. Coluna Anúncios, v.63, n.335, p.7. 2 dez. 1885.

JORNAL DO COMMERCIO.

[Rio de Janeiro]. Coluna Anúncios, v.64, n.20, p.5. 20 jan. 1885 .

JORNAL DO COMMERCIO.

[Rio de Janeiro]. Coluna Anúncios, v.64, n.4, p.5. 4 jan. 1885 .

JORNAL DO COMMERCIO.

[Rio de Janeiro]. Coluna Anúncios, v.59, n.344, p.5. 11 dez. 1880.

JORNAL DO COMMERCIO.

[Rio de Janeiro]. Coluna Anúncios, v.59, n.22, p.4. 22 jan. 1880 . 
JORNAL DO COMMERCIO.

[Rio de Janeiro]. Coluna Anúncios, v.49, n.333, p.5-6. 3 dez. 1870.

\section{JORNAL DO COMMERCIO.}

[Rio de Janeiro]. Coluna Anúncios, v.49, n.149, p.3. 1 jun. 1870 .

\section{JORNAL DO COMMERCIO.}

[Rio de Janeiro]. Coluna Anúncios, v.43, n.180, p.4. 30 jun. 1865.

\section{JORNAL DO COMMERCIO.}

[Rio de Janeiro]. Coluna Anúncios, v.43, n.177, p.3. 27 jun. 1865.

\section{JORNAL DO COMMERCIO.}

[Rio de Janeiro]. Coluna Anúncios, v.35, n.155, p.4. 5 jun. 1860.

JORNAL DO COMMERCIO.

[Rio de Janeiro]. Coluna Anúncios, v.30, n.157, p.4. 8 jun. 1855.

\section{JORNAL DO COMMERCIO.}

[Rio de Janeiro]. Coluna Anúncios, v.25, n.18, p.4. 18 jan. 1850 .

\section{JORNAL DO COMMERCIO.}

[Rio de Janeiro]. Coluna Anúncios, v.15, n.322, p. 4.5 dez. 1840 .

\section{JORNAL DO COMMERCIO.}

[Rio de Janeiro]. Coluna Anúncios, v.15, n.150, p.4. 3 jun. 1840 .

\section{JORNAL DO COMMERCIO.}

[Rio de Janeiro]. Coluna Anúncios, v.9, n.126, p.3-4. 9 jun. 1835.

\section{JORNAL DO COMMERCIO.}

[Rio de Janeiro]. Coluna Anúncios, v.9, n.13, p.3. 17 jan. 1835.

MARTINS, Ana Paula Vosnes.

A medicina da mulher: visões do corpo feminino na constituição da obstetrícia e da ginecologia no século XIX. Tese (Doutorado) - Instituto de Filosofia e Ciências Humanas, Universidade Estadual de Campinas, Campinas. 2000.

MEDEIROS, Helber Renato Feydit.

Parteiras e médicos: a disputa por espaços na arte de partejar e a formação de obstetrizes na Faculdade de Medicina do Rio de Janeiro no século XIX. Tese (Doutorado) - Programa de Pós-graduação em Saúde Coletiva, Universidade Federal do Rio de Janeiro, Rio de Janeiro. 2015.
MOTT, Maria Lucia de Barros.

Parteiras: o outro lado da profissão. Revista Gênero, v.6, n.1, p.117-140. 2005.

MOTT, Maria Lucia de Barros.

Parteiras no século XIX: Mme. Durocher e sua época. In: Costa, Albertina de Oliveira; Bruschini, Cristina. Entre a virtude e o pecado. Rio de Janeiro: Rosa dos Tempos, Fundação Carlos Chagas. p.37-56. 1992.

PIMENTEL, Alberto.

O melhor casamento. Lisboa: Guimarães e Cia. Disponível em: http:// booksnow1.scholarsportal.info/ebooks/ oca7/34/omelhorcasamento00pime/ omelhorcasamento00pime.pdf . Acesso em: 8 out. 2015 . s.d.

ROHDEN, Fabíola.

Histórias e tensões em torno da medicalização da reprodução. Revista Gênero, v.6, n.1, p.213224. 2006.

ROHDEN, Fabíola.

Uma ciência da diferença: sexo e gênero na medicina da mulher. Rio de Janeiro: Fiocruz. 2001.

SANTOS FILHO, Lycurgo. História da medicina no Brasil: do século XVI ao século XIX. t.2. São Paulo: Brasiliense. 1947.

SIGAUD...

Sigaud, José Francisco Xavier. Dicionário Histórico-Biográfico das Ciências da Saúde no Brasil (1832-1930). Disponível em: http://www. dichistoriasaude.coc.fiocruz.br/iah/pt/verbetes/ sigjoxav.htm. Acesso em: 10 jan. 2015. s.d.

SILVA, Marinete dos Santos. Clientes e circuitos da prostituição no Rio de Janeiro do século XIX. Dimensões, v.29, n.29, p.374-391. 2012a.

SILVA, Marinete dos Santos.

Reprodução, sexualidade e poder: as lutas e disputas em torno do aborto e da contracepção no Rio de Janeiro, 1890-1930. História, Ciências, Saúde-Manguinhos, v.19, n.4, p.1241-1254. 2012b.

SOUZA, Maria Lucia de Barros Mott de Melo. Parto, parteiras e parturientes: Mme. Durocher e sua época. São Paulo. Tese (Doutorado em História) - Programa de Pós-Graduação em História, Universidade de São Paulo, São Paulo. 1998.

\section{$\rightarrow \rightarrow \rightarrow<<<$}

